\title{
Audit Energi dan Analisis Peluang Penghematan Energi di PT. Daikin Air Conditioning Makassar
}

\author{
Purwito $^{1, \mathrm{a}}$, Tadjuddin ${ }^{1, \mathrm{~b}}$, Akbar $^{1, \mathrm{c}}$ \\ ${ }^{1}$ Electrical Engineering Department, State Polytechnic of Ujung Pandang, Jl.Perintis Kemerdekaan Km10.Tamalanrea Makassar, \\ 90245, Indonesia. \\ a purwitopnup@gmail.com \\ b tadjuddin246@yahoo.com \\ cakbar@gmail.com
}

\begin{abstract}
Energy audit is an activity to identivy how much energy is used as well as the steps that are needed in order to concerve energy on an energy user facility. PT. Daikin Air Conditioning Makassar using air conditioning equipments that uses electrical energy nearly $60 \%$. This study aims to determine the used of electrical energy and energy saving opportunities in PT. Daikin Air Conditioning Makassar. Reseacrh is started with processing of electrical equipment data for lighting, air conditioning and other electrical equipments data. Research result pointed that the used of electric energyin PT. Daiking Air Conditioning Makassar is $111.3 \mathrm{kWh} / \mathrm{m}^{2} /$ year and still below the standart of IKE and can be savingabout $44 \mathrm{kWH} / \mathrm{month}$ for lighting system. Recommendations are to perform load balancing each phase, turn on the light and air condioning only when needed.
\end{abstract}

\section{Keywords-Energy audit; IKE standard; Recommendation.}

\begin{abstract}
Audit energi adalah kegiatan untuk mengidentifikasi seberapa banyak energi yang digunakan serta langkah-langkah yang diperlukan untuk menghemat energi pada fasilitas pengguna energi. PT. Daikin Air Conditioning Makassar menggunakan peralatan AC yang menggunakan energi listrik hampir $60 \%$. Penelitian ini bertujuan untuk mengetahui penggunaan energi listrik dan peluang penghematan energi di PT. Daikin Air Conditioning Makassar. Reseacrh dimulai dengan pengolahan data peralatan listrik untuk penerangan, AC dan data peralatan listrik lainnya. Hasil penelitian menunjukkan bahwa penggunaan energi listrik pada PT. Daiking Air Conditioning Makassar adalah 111,3 kWh / m2 / tahun dan masih di bawah standar IKE dan dapat menghemat sekitar 44 kWH / bulan untuk sistem pencahayaan. Rekomendasi adalah untuk melakukan load balancing setiap fase, hidupkan cahaya dan udara hanya jika diperlukan.
\end{abstract}

Keywords-Audit Energi; Standar IKE; Rekomendasi.

\section{Pendahuluan}

Energi listrik sangat penting dalam duniaindrustri danperkantoran. Di PT. Daikin Air conditioning cabang Makassar, Peralatan pengkondisian udara merupakan peralatan yang banyakmengkonsumsi energi listrik. Hampir 60\%energi listrik digunakan untuk sistem pengkondisian udara. Untuk menanggulangi masalah tersebut dilakukan efisiensi energy melalui konservasi energy, yaitu peningkatan efisiensi energi atau proses penghematan energi. Proses ini meliputiaudit energi yaitu menghitung tingkat konsumsi energi suatu gedung atau bangunan.

Pada PT. Daikin Air Conditioning terlihat bahwa konsumsi energi listrik dapat mencapai kuranglebih $90 \%$. Oleh sebab itu perlu dilakukan penghematan energi untuk menekan biayapemakaian enrgi listrik di PT. Daikin Air Conditioning Makassar.Tujuan dari Penelitian ini adalah untuk mengetahui pemakaian energi listrik danpeluang penghematanenergi di PT. Daikin Air Conditioning Makassar.

\section{A. Audit Energi}

Energi adalah suatu besaran yang secara konseptual dihubungkan dengan transformasi, proses atau perubahan yang terjadi. Besaran ini seringkali dikaitkan dengan perpindahan sebuah gaya atau perubahan temperature sehingga memungkinkan penentuan satuan joule (perpindahan gaya 1 Newton sejauh 1 meter), maupun kalor jenis (energi yang dibutuhkan untuk menaikkan temperatur sebesar 1 derajat per satuan massa material). Dalam keperluan praktis, energi sering kali dikaitkan dengan jumlah bahan bakar atau konsumsi jumlah listrik. (Badan Koordinasi Energi Nasional, 1983) [1]. 
Setiap zat mengandung sejumlah energi yang disebut energi dalam. Dalam suatu proses zat dapat melepaskan sebagian energi dalamnya (dalam proses pembakaran) atau menyimpan energi yang berasal dari lingkungan (pemanasan suatu zat) [2],[3].

Secara umum audit energi adalah kegiatan untuk mengidentifikasi dimana dan berapa energi yang digunakan serta langkah - langkah apa yang dapatdilakukan dalam rangka konservasi energi pada suatu fasilitas pengguna energi.

Menurut Peraturan Menteri Energi dan Sumber Daya Mineral Republik IndonesiaNomor 14 Tahun 2010, Audit Energi adalah proses evaluasi pemanfaatan energi dan identifikasi peluang pengehematan energi serta rekomendasi peningkatan efisiensi pada pengguna sumber energi dan pengguna energi dalam rangkakonservasi energi [4]. Adapunkarkteristik yang harus ada pada audit adalah: 1). Fokus, 2). Ruang lingkup, 3). Level of detail.

\section{B. Macam-Macam Audit Energi}

Audit energi bukan hanya satu jenis saja, melainkanbermacam-macam jenis, dantiap jenis memiliki fungsi masing-masing. Adapun jenis-jenis audit energi tersebut dapat dibagai menjadi beberapa bentuk, seperti walking audit, preliminary audit, deteiled audit, energy management plan and implementation action [2].

Tahapan untuk melakukan suatu audit energi yang sederhana, kususnya untuk gedung bertingkat adalah: a). Menetapkan batasan masalah, b). Membentuk sebuah tim audit, c). Analisis kondisi actual, d). Menghitung penghematan, e). Laporan audit, f). Analisis penghematan, dan g). Eavluasi penghematan.

\section{Nilai Intensitas Konsumsi Energi(IKE}

Salah satu ukuran hemat tidaknya suatu bangunan dalam memakai energi adalah Intensitas Konsumsi Energi (IKE). IKE adalah perbandingan antara konsumsi energi dengan satuan luas bangunan gedung [5].

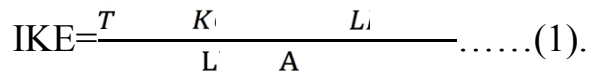

IKE dalam satuan $\left(\mathrm{kWh} / \mathrm{m}^{2}\right)$. Pemakaian IKE ini telah ditetapkan di berbagai negara antara lain ASEAN dan APEC.

Perhitungan IKE menggunakan hasil penelitian ASEAN - USAID. Standar IKE untuk gedung perkuliahan adalah $240 \mathrm{kWh} / \mathrm{m} 2$ per tahun.Nilai dari IKE ini adalah standar pada tahun 1992 yang diterapkan pada SNI 05-3052-1992 [6].
Potensi penghematan merupakan hasil analisis Intensitas Konsumsi Energi untuk selanjutnya dibandingkan dengan standar yang digunakan (SNI, BSN), jika didapati IKE lebih besar dari IKE standar maka potensi penghematan adalah sebesar:

$$
\frac{(\Delta \mathrm{IKE} \times \text { tarif listrik) }}{1 \text { tahun }(12 \text { bulan })} \ldots \ldots(
$$

\section{Potensi Penghematan}

Pada hakekatnya Intensitas Konsumsi Energi ini adalah hasil bagi antara konsumsi energi total selama periode tertentu (satu tahun) dengan luasan bangunan. Satuan IKE adalah $\mathrm{kWH} / \mathrm{m}^{2}$ per tahun.

Menurut hasil penelitian yang dilakukan oleh ASEAN-USAID pada tahun 1987 yang laporannya baru dikeluarkan tahun 1992, target besarnya Intensitas Konsumsi Energi (IKE) listrik untuk Indonesia adalah sebagai berikut (Direktorat Pengembangan Energi) [7]:

1. IKE untuk perkantoran (komersil): $240 \mathrm{kWH} / \mathrm{m}^{2}$ per tahun

2. IKE untuk pusat belanja: $330 \mathrm{kWH} / \mathrm{m}^{2}$ per tahun

3. IKE untuk hotel / apartemen : $300 \mathrm{kWH} / \mathrm{m}^{2}$ per tahun

4. IKE untuk rumah sakit: $380 \mathrm{kWH} / \mathrm{m}^{2}$ per tahun.

\section{E. Sistem Pengkondisian Udara}

Audit energi sistem tata udara bertujuan untuk mengetahui kondisi suhu dan kelembaban dalam suatu ruangan dan mengetahui efisiensi penggunaan peralatan penyejuk udara.

\section{F. Sistem Penerangan}

Sistem penerangan harus dirancang sedemikian rupa sehingga dapat memanfaatkan cahaya matahari sebagai cahaya sumber alami secara maksimal, agar pemakaian energi listrik untuk penerangan bisa seminimal mungkin. Aspek-aspek yang perlu diperhatikan dalam sistem penerangan: i). Penentuan Intensitas cahaya, ii). Pemakaian sumber dan iii). Pemusatan/pengarahan cahaya.

\section{G. Mengenali kemungkinan Peluang Hemat Energi (PHE)}

Hasil pengukuran selanjutnya ditindaklanjuti dengan perhitungan besarnya IKE dan penyusunan profil penggunaan energi bangunan. Besarnya IKE hasil perhitungan dibandingkan dengan IKE standar atau target IKE.

Apabila peluang hemat energi ini telah dikenali sebelumnya, maka perlu ditindak lanjuti dengan analisis 
peluang hemat energi, dengan cara membandingkan potensi perolehan hemat energi dengan biaya yang harus dibayar untuk pelaksanaan rencana penghematan energi yang direkomendasikan. Penghematan energi pada bangunan gedung tidak dapat diperoleh begitu saja dengan cara mengurangi kenyamanan penghuni ataupun produktivitas di lingkunan kerja. Perlu dilakukan usahausaha seperti: Mengurangi sekecil mungkin pemakaian energi (mengurangi $\mathrm{kW}$ dan jam operasi), memperbaiki kinerja peralatan, penggunaan sumber energi yang murah.

\section{H. Rekomendasi}

Setelah melakukan survey dan menganalisa data penggunaan energi pada suatu plant, auditor energi akan memberikan beberapa rekomendasi pada perusahan, yang merupakanusulan- usulan yang dapat dilakukan perusahaan untuk memperbaiki efisiensi penggunaan energi di perusahaan tersebut [8],[9].

\section{Metode Penelitian}

A. Tempat dan waktu

Penelitian ini dilakukan di PT. Daikin Air Conditioning cabang Makassar Jl. A.P. Pettarani selama 8 bulan.

\section{B. Alat dan Bahan}

Dalam penelitian ini digunakan alat dan bahan berupa: thermometer,Luxmeter dan tang Ampere.

\section{Teknik Pengumpulan Data}

Pengumpulan data dilakukan dengan observasi secara langsung di lapangan.

\section{Hasil dan Pembahasan}

\section{A. Audit Energi Awal}

Dalam perhitungan audit energi awal ini, dicari nilai IKE dengan memanfaatkan data historis energi (data yang diperoleh tanpa hasil pengukuran) serta data - data bangunan serta luasan area. Dalam analisis iniditampilkan gambaran siklus pemanfaatan energi serta jumlah pemakaian energi listrik selama setahun. Apabila standar IKE belum terpenuhi maka pelaksanaan audit energi akan dilanjutkan ke tahap selanjutnya yaitu audit energi rinci.

\section{B. Ukuran dan Fungsi Ruang}

Ukuran tiap ruang pada gedung dapat dilihat padatabel berikut.
Tabel 1. Komposisi luas bangunan kantor PT. Daikin Air

\begin{tabular}{|c|c|c|c|}
\hline \multicolumn{4}{|c|}{ Conditioning } \\
\hline No & Lantai & Area & Luas (m2) \\
\hline 1 & \multirow{4}{*}{1} & Teras depan & 6,4 \\
\hline 2 & & Show room & 31,7 \\
\hline 3 & & Workshop & 17,4 \\
\hline 4 & & Toilet & 2,1 \\
\hline 5 & \multirow{4}{*}{2} & R. Spare part & 50 \\
\hline 6 & & R. Penyimpanan & 25 \\
\hline 7 & & Teras depan & 3 \\
\hline 8 & & Toilet & 2,1 \\
\hline 9 & \multirow{4}{*}{3} & R. Spare part & 50 \\
\hline 10 & & R. Penyimpanan & 25 \\
\hline 11 & & Teras depan & 3 \\
\hline 12 & & Toilet & 2,1 \\
\hline \multicolumn{3}{|c|}{ TOTAL } & 225,6 \\
\hline
\end{tabular}

C. Sistem Distribusi Energi

PT. Daikin Air Conditioning Cabang Makassar menggunkan energi listrik. Dalam rangka kebutuhan energi ini mekanisme yang dipakai untuk pengadaannya bisa dijelaskan sebagai berikut. Untuk memenuhi kebutuhan energi tersebut menggunakan sumber energi listrik yang disupply dari PLN dengan 16.500 VA yang berada pada golongan tarif Bisnis B2/TR.

Berikut ini adalah data hasil pengukuran tegangan dan arus pada panel induk di kantor PT. Daikin Air conditioning Makassar yaitu: tegangan phasa-netral dan arus masing-masing $\mathrm{V}_{\mathrm{R}-\mathrm{N}=} 215$ volt; $18,84 \mathrm{~A} ; \mathrm{V}_{\mathrm{S}-\mathrm{N}}=216$ volt; 12,5 A dan $\mathrm{V}_{\mathrm{T}-\mathrm{N}}=221$; volt 7,3 $\mathrm{A}$.

\section{Data Konsumsi Energi}

Berikut ini adalah data-data konsumsi energi serta alokasinya di kantor PT. Daikin Air Conditioning cabang Makassar selama satu tahun.

Tabel 2. Data RekeningKonsumsi Energi Listrik selama 1 tahun

\begin{tabular}{|c|c|c|}
\hline Bulan & Total kWH & Pembayaran (Rp) \\
\hline Oct & 2,907 & $4,500,000$ \\
\hline 14-Nov & 2,261 & $3,500,000$ \\
\hline 14-Dec & 1,518 & $2,351,000$ \\
\hline 15-Jan & 1,680 & $2,601,000$ \\
\hline 15-Feb & 1,634 & $2,530,000$ \\
\hline 15-Mar & 2,584 & $4,000,000$ \\
\hline 15-Apr & 1,485 & $2,300,000$ \\
\hline 15-May & 1,938 & $3,000,000$ \\
\hline 15-Jun & 2,261 & $3,500,000$ \\
\hline 15-Jul & 2,261 & $3,500,000$ \\
\hline 15-Aug & 2,261 & $3,500,000$ \\
\hline 15-Sep & 1,938 & $3,000,000$ \\
\hline & $\mathbf{2 4 , 7 8 2}$ & $\mathbf{3 8 , 2 8 2 , 0 0 0}$ \\
\hline
\end{tabular}

E. Data peralatan listrik

1. Data Peralatan Penerangan

Data peralatan penerangan yang digunakanadalah seperti pada tabel 3 . 
Tabel 3. Data Peralatan Penerangan

\begin{tabular}{|c|c|c|c|c|c|}
\hline No & Lantai & Ruang & $\begin{array}{c}\text { Daya Lampu } \\
\text { (watt) }\end{array}$ & Qty & $\begin{array}{c}\text { Jml Jam } \\
\text { nyala }\end{array}$ \\
\hline 1 & \multirow{4}{*}{1} & Teras depan & Sinyoku 23 watt & 1 & 14 \\
\hline 2 & & Show room & Sinyoku 23 watt & 4 & 9 \\
\hline 3 & & Workshop & Sinyoku 23 watt & 4 & 9 \\
\hline 4 & & Toilet & Sinyoku 23 watt & 1 & 9 \\
\hline 5 & \multirow{5}{*}{2} & Office & Sinyoku 23 watt & 4 & 9 \\
\hline 6 & & Meeting room & Sinyoku 23 watt & 4 & 2 \\
\hline 7 & & R.Server & Sinyoku 23 watt & 1 & 1 \\
\hline 8 & & Pantry & Sinyoku 23 watt & 2 & 9 \\
\hline 9 & & Toilet & Sinyoku 23 watt & 1 & 9 \\
\hline 10 & \multirow{4}{*}{3} & Spare part & Sinyoku 23 watt & 4 & 2 \\
\hline 11 & & Penyimpanan & Sinyoku 23 watt & 1 & 2 \\
\hline 12 & & Teras depan & Sinyoku 23 watt & 1 & 2 \\
\hline 13 & & Toilet & Sinyoku 23 watt & 1 & 2 \\
\hline
\end{tabular}

2. Data peralatan sistem tata udara

Data peralatan sistem tata udara dapat dilihat pada tabel 4.

3. Data komsumsi energi listrik

Dari data yang tertera pada tabelberikut langsung dapat dihitung jumlah KWh totalyang dikonsumsi kantor PT. DaikinAirconditioning Makassarselama se tahun dan juga total yang harus dibayar untuk pada periode tersebut. Total KWh adalah $24,782 \mathrm{KWh}$ dan ini senilai dengan Rp 38,282,000.

Tabel 4a. Data peralatan pengkondisian udara

\begin{tabular}{|c|c|c|c|c|c|c|c|c|}
\hline No & Lantai & Ruangan & Merk & Type & $\begin{array}{c}\text { Kapasitas } \\
\text { (btu) }\end{array}$ & DAYA (Wat) & Qty & Jam Operasi/hari \\
\hline 1 & \multirow{4}{*}{1} & Teras depan & - & - & - & & - & - \\
\hline 2 & & Show room & Daikin & FCQ50LUV1 & 17100 & 1040 & 4 & 9 \\
\hline 3 & & Workshop & Daikin & FT25HEV1 & 9000 & 690 & 4 & 9 \\
\hline 4 & & Toilet & - & - & - & & - & - \\
\hline 5 & \multirow{4}{*}{2} & Office & Daikin & FTKD50GVM & 17700 & 1580 & 4 & 9 \\
\hline 6 & & Meeting room & Daikin & FT25HV1 & 8900 & 690 & 4 & 2 \\
\hline 7 & & R. server & Daikin & FT15LV1 & 5000 & 380 & 1 & 1 \\
\hline 8 & & Pantry & - & - & - & - & - & - \\
\hline 9 & \multirow{5}{*}{3} & Toilet & - & - & - & - & - & - \\
\hline 10 & & R. Spare part & - & - & - & - & - & - \\
\hline 11 & & R. Penyimpanan & - & - & - & - & - & - \\
\hline 12 & & Teras depan & - & - & - & - & - & - \\
\hline 13 & & Toilet & - & - & - & - & - & - \\
\hline
\end{tabular}

Tabel 4b. Data peralatan listrik selain penerangan dan tata udara

\begin{tabular}{|c|c|c|c|c|c|c|c|c|}
\hline No & Lantai & Ruangan & Merk & Type & $\begin{array}{c}\text { Kapasitas } \\
\text { (btu) }\end{array}$ & DAYA (w) & Qty & $\begin{array}{c}\text { Jam Operasi } \\
\text { /hari }\end{array}$ \\
\hline 1 & \multirow{4}{*}{1} & Teras depan & - & - & - & & - & - \\
\hline 2 & & Show room & Daikin & FCQ50LUV1 & 17100 & 1040 & 4 & 9 \\
\hline 3 & & Workshop & Daikin & FT25HEV1 & 9000 & 690 & 4 & 9 \\
\hline 4 & & Toilet & - & - & - & & - & - \\
\hline 5 & \multirow{5}{*}{2} & Office & Daikin & FTKD50GVM & 17700 & 1580 & 4 & 9 \\
\hline 6 & & Meeting room & Daikin & FT25HV1 & 8900 & 690 & 4 & 2 \\
\hline 7 & & R. server & Daikin & FT15LV1 & 5000 & 380 & 1 & 1 \\
\hline 8 & & Pantry & - & - & - & - & - & - \\
\hline 9 & & Toilet & - & - & - & - & - & - \\
\hline 10 & \multirow{4}{*}{3} & R. Spare part & - & - & - & - & - & - \\
\hline 11 & & R. Penyimpanan & - & - & - & - & - & - \\
\hline 12 & & Teras depan & - & - & - & - & - & - \\
\hline 13 & & Toilet & - & - & - & - & - & - \\
\hline
\end{tabular}

\section{F. Analisis Tingkat Kuat Penerangan}

Dari hasil penelitian diketahui bahwa sebagian besar aktifitas di PT. Daikin Airconditioning cabang Makassar dilakukan pada siang hari. Ruang-ruangan kantor PT. Daikin Air Conditioning cabang Makassar menggunakan penerangan lampu. Hanya di tempat tempat tertentu mengunakan penerangan alami.

Perbandingan tingkat kuat penerangan hasil pengukuran dengan standar yang sudah ditetapkandalam SNI 03-6197-2000 untuk beberapa sampel ruangan dapat dilihat pada tabel 5 . 
Tabel 5. Hasil Pengukuran Kuat Penerangan

\begin{tabular}{|c|c|c|c|c|}
\hline \multirow[b]{2}{*}{ No. } & \multirow[b]{2}{*}{ RUANG } & \multicolumn{2}{|c|}{ LUX } & \multirow[b]{2}{*}{ Ket. } \\
\hline & & terukur & $\begin{array}{l}\text { Standar } \\
\text { SNI }\end{array}$ & \\
\hline 1 & Teras depan & 62 & 50 & $<\mathrm{SNI}$ \\
\hline 2 & Show room & 230 & 500 & $<\mathrm{SNI}$ \\
\hline 3 & Workshop & 210 & 500 & $<\mathrm{SNI}$ \\
\hline 4 & Toilet & 139 & 250 & $<\mathrm{SNI}$ \\
\hline 5 & Office & 170 & 350 & $<\mathrm{SNI}$ \\
\hline 6 & Meeting room & 200 & 300 & $<\mathrm{SNI}$ \\
\hline 7 & Server & 200 & 300 & $<\mathrm{SNI}$ \\
\hline 8 & Pantry & 174 & 300 & $<\mathrm{SNI}$ \\
\hline 9 & Toilet & 139 & 250 & $<\mathrm{SNI}$ \\
\hline 10 & Spare part & 200 & 300 & $<\mathrm{SNI}$ \\
\hline 11 & Penyimpanan & 150 & 150 & $=\mathrm{SNI}$ \\
\hline 12 & Teras depan & 60 & 50 & $>\mathrm{SNI}$ \\
\hline 13 & Toilet & 139 & 250 & $<\mathrm{SNI}$ \\
\hline
\end{tabular}

Dari tabel 5 diketahui bahwa hampir semua ruangan yang ada dikantor PT. Daikin Air Conditioning cabang Makassar, tingkat kuat penerangannya berada dibawah standar yang telah ditetapkan dalam SNI 03-6575.2001.
Untuk sistem pencahayaan/ penerangan komsumsi rata-rata perbulan $91.59 \mathrm{kWh}$.

\section{G. Analisis Sistem Tata Udara}

Hasil perhitungan kapasitas AC yang ideal dan hasil pengukuran suhu dan kelembaban udara untuk beberapa sampel ruangan pada kantor PT. Daikin Airconditioning cabang Makassar dapat dilihatpada tabel 7.

\section{H. Analisis Sistem Tata Udara}

Hasil perhitungan dan pengukuran suhuberkisar antara $22^{\circ} \mathrm{C}-25^{\circ} \mathrm{C}$ dengan kelembaban udara pada beberapa ruangan sebagai sampeladalah antara 57\%$75 \%$. Berdasarkan standar yang ditetapkan SNI 036572 2001 mengenai kenyamanan pengkondisian udara, data pada tabel 8 menunjukkan bahwa suhu dan kelembaban udara telah memenuhi standar.

\section{Pemakain listrik pada peralatan kantor}

Data komsumsi pemakain listrik pada peralatan kantor dapat lihat pada table 8 .

Tabel 6. Total Konsumsi Energi Listrik Pencahayaan Per Hari

\begin{tabular}{|c|c|c|c|c|c|c|}
\hline No. & Ruang & Daya (watt) & Jam nyala & Jml hari/bulan & Qty & Total komsumsi/hari \\
\hline 1 & Teras depan & 23 & 14 & 22 & 1 & 0,32 \\
\hline 2 & Show room & 23 & 9 & 22 & 4 & 0,83 \\
\hline 3 & Workshop & 23 & 9 & 22 & 4 & 0,83 \\
\hline 4 & Toilet & 23 & 9 & 22 & 1 & 0,21 \\
\hline 5 & Office & 23 & 9 & 22 & 4 & 0,83 \\
\hline 6 & Meeting room & 23 & 2 & 22 & 4 & 0,18 \\
\hline 7 & R. server & 23 & 1 & 22 & 1 & 0,02 \\
\hline 8 & Pantry & 23 & 9 & 22 & 2 & 0,41 \\
\hline 9 & Toilet & 23 & 9 & 22 & 1 & 0,21 \\
\hline 10 & R. Spare part & 23 & 2 & 22 & 4 & 0,18 \\
\hline 11 & R. Penyimpanan & 23 & 2 & 22 & 1 & 0,05 \\
\hline 12 & Teras depan & 23 & 2 & 22 & 1 & 0,05 \\
\hline 13 & Toilet & 23 & 2 & 22 & 1 & 0,05 \\
\hline \multicolumn{6}{|c|}{ Rata-rata hari kerja perbulan } & 22 \\
\hline \multicolumn{6}{|c|}{ Total komsumsi perhari $(\mathrm{kWH})$} & 4.16 \\
\hline \multicolumn{6}{|c|}{ Total komsumsi rata-rata perbulan (kWH) } & 91.59 \\
\hline \multicolumn{6}{|c|}{ Total komsumsi pertahun (kWH) } & $1,099.03$ \\
\hline
\end{tabular}

Tabel 7. Konsumsi Energi Listrik Air Conditioner (AC)

\begin{tabular}{|c|c|c|c|c|c|c|c|c|c|}
\hline \multirow[t]{2}{*}{ No } & \multirow[b]{2}{*}{ Ruangan } & \multirow{2}{*}{$\begin{array}{c}\text { Jmlh } \\
\text { (buah) }\end{array}$} & \multicolumn{2}{|c|}{ Kapasitas } & \multirow{2}{*}{$\begin{array}{c}\text { Lama operasi } \\
\text { Jam } \\
\end{array}$} & \multirow[t]{2}{*}{ Jml hari/ bulan } & \multirow{2}{*}{$\begin{array}{c}\text { Suhu terukur } \\
\left({ }^{\circ} \mathrm{C}\right)\end{array}$} & \multirow[t]{2}{*}{ RH (\%) } & \multirow{2}{*}{$\begin{array}{c}\text { Komsumsi } \\
(\text { kWH) }\end{array}$} \\
\hline & & & Watt & $\mathrm{PK}$ & & & & & \\
\hline 1 & Sowroom & 1 & 1040 & 2 & 9 & 22 & 25 & 60 & 9.4 \\
\hline 2 & Workshop & 1 & 690 & 1 & 9 & 22 & 25 & 65 & 6.2 \\
\hline 3 & Office & 1 & 1580 & 2 & 9 & 22 & 23 & 75 & 14.2 \\
\hline 4 & Meeting room & 1 & 690 & 1 & 9 & 22 & 25 & 63 & 6.2 \\
\hline 5 & R.Server & 1 & 380 & $1 / 2$ & 24 & 30 & 22 & 57 & 9,1 \\
\hline \multicolumn{9}{|c|}{ Rata-rata hari pemakaian } & 24 \\
\hline \multicolumn{9}{|c|}{ Total komsumsi harian (kWH) } & 45.12 \\
\hline \multicolumn{9}{|c|}{ Rata-rata komsumsi/bulan (kWH) } & $1,064.83$ \\
\hline \multicolumn{9}{|c|}{ Rata-rata komsumsi Tahunan (kWH } & $12,777.98$ \\
\hline
\end{tabular}


Tabel 8. Pemakain listrik pada peralatan kantor lainnya

\begin{tabular}{|c|c|c|c|c|c|c|}
\hline No & Nama Peralatan & Daya (Watt) & Qty & Jam Nyala & Jml hari /bulan & KomsumsiEnergi (kWH) \\
\hline 1. & TV & 335 & 1 & 3 & 22 & 1.005 \\
\hline 2. & PC & 160 & 14 & 9 & 22 & 20.16 \\
\hline 3 & Exhaust & 65 & 3 & 24 & 30 & 4.68 \\
\hline 4. & Printer & 35 & 3 & 2 & 22 & 0.21 \\
\hline 5 & Mesin fotocopi & 1760 & 1 & 3 & 22 & 5.28 \\
\hline 6 & Projector & 264 & 1 & 2 & 22 & 0.528 \\
\hline 7 & Dispenser & 350 & & 12 & 22 & 4.2 \\
\hline 8 & Dispenser & 390 & 1 & 12 & 22 & 4.68 \\
\hline \multicolumn{8}{|c|}{ Rata-rata hari kerja /bulan } & $\mathbf{2 3}$ \\
\hline \multicolumn{8}{|c|}{ Total komsumsi perhari } \\
\hline
\end{tabular}

Berdasarkan data hasil analisa dan perhitungan pemakaian energy listrik PT. Daikin Airconditioning cabang Makassar diperoleh komsumsi energy selama 1 tahun terakhir sebagai berikut:

1. Sytem pencahayaan:1.099.03 kWh/Tahun.

2. Sytem tata udara: $12.777 .98 \mathrm{kWh} /$ Tahun.

3. Peralatan kantorLainnya:11.245.07 kWh/Tahun.

\section{J. Intensitas Komsumsi Energi (IKE)}

Dari data konsumsi energi dan data luasan bangunan, maka dapat dihitung besarnya IKE Kantor PT. Daikin Airconditioning cabang Makassar selama 1 tahun dengan persamaansebagai berikut:

$$
\begin{array}{cc}
\text { Ii } & =\frac{\text { Total } \mathrm{kWh}}{\text { Luas Bangunan }} \ldots \ldots \ldots \text { (3) } \\
\text { Ii } \quad=\frac{25122 \mathrm{kWh}}{225,6 \mathrm{~m}^{2}}=111,3 \mathrm{kWh} / \mathrm{m}^{2} / \text { Tahun }
\end{array}
$$

Tabel 9. Perbandingan Konsumsi Energi Pencahayaan Sebelum dan

\begin{tabular}{|c|c|c|c|c|c|}
\hline \multirow[b]{2}{*}{ No } & \multirow[b]{2}{*}{ Ruangan } & \multicolumn{2}{|c|}{$\begin{array}{c}\text { Total Komsumsi Kwh per } \\
\text { hari }\end{array}$} & \multirow{2}{*}{$\begin{array}{c}\text { Penghemata } \\
\text { nkWH per } \\
\text { hari }(k W H)\end{array}$} & \multirow{2}{*}{$\begin{array}{c}\text { Total } \\
\text { Penghemata } \\
\text { n } \\
\text { Perbulan(k } \\
\text { WH) } \\
\end{array}$} \\
\hline & & $\begin{array}{l}\text { Sebelum } \\
\text { penghemat } \\
\text { an }\end{array}$ & $\begin{array}{c}\text { Sebelum } \\
\text { penghemata } \\
\mathbf{n}\end{array}$ & & \\
\hline (1) & $(2)$ & (3) & (4) & $(5)$ & (6) \\
\hline 1 & Teras depan & 0.32 & 0.06 & 0.26 & 5.72 \\
\hline 2 & Show room & 0.83 & 0.65 & 0.18 & 3.96 \\
\hline 3 & Workshop & 0.83 & 0.36 & 0.47 & 10.34 \\
\hline 4 & Toilet & 0.21 & 0.04 & 0.17 & 3.74 \\
\hline 5 & Office & 0.83 & 043 & 0.4 & 8.8 \\
\hline 6 & $\begin{array}{l}\text { Meeting } \\
\text { room }\end{array}$ & 0.18 & 0.07 & 0.11 & 2.42 \\
\hline 7 & R. server & 0.02 & 0.01 & 0.01 & 0.22 \\
\hline 8 & Pantry & 0.41 & 0.32 & 0.09 & 1.98 \\
\hline 9 & Toilet & 0.21 & 0.04 & 0.17 & 3.74 \\
\hline (1) & $(2)$ & (3) & (4) & (5) & (6) \\
\hline 10 & R. Spare part & 0.18 & 0.12 & 0.06 & 1.32 \\
\hline 11 & $\begin{array}{l}\text { R. } \\
\text { Penyimpanan }\end{array}$ & 0.05 & 0.05 & 0 & 0 \\
\hline 12 & Teras depan & 0.05 & 0.01 & 0.04 & 0.88 \\
\hline 13 & Toilet & 0.05 & 0.01 & 0.04 & 0.88 \\
\hline \multicolumn{2}{|c|}{$\begin{array}{l}\text { Total komsumsi } \\
\text { (Kwh)/ hari }\end{array}$} & 4.17 & 2.17 & 2 & 44 \\
\hline
\end{tabular}
setelah penghematan
Adapun nilai target IKEyang digunakan yaitu standar IKE Asean-Usaid tahun 1992 dimana untukperkantoran yaitu $240 \mathrm{kWh} / \mathrm{m}^{2} /$ Tahun, maka dapat dikatakan dari data perhitungan IKE listrik per satuan luas bangunan dan berdasarkan data konsumsi energi dari rekening pembayaran listrik selama 1 tahun sebesar 4,89 $\mathrm{kWh} / \mathrm{m}^{2} /$ bulan atau $111,3 \mathrm{kWh} / \mathrm{m}^{2} /$ Tahun. Angka ini masih dibawah standar/target IKE yang ditentukan sehingga dapat dikatakan bahwa nilai IKE masih efisien.

\section{K. Rekomendasi}

1. Melakukan penyeimbangan beban pada tiap phase.

2. Peluang peningkatan efisiensi penerangan padaruangan, showroom, workshop, toilet, office, meeting room, pantry, ruang spare part, ruang penyimpanan perlu diperhatikan hal-hal berikut:

a. Menyalakan lampu hanyapada saat dibutuhkan,

b. Mengganti lampu dengan lampu LED yang lebih hemat energi dan intensitas cahayanya lebih besar.

3. Efisiensi Tata Udara (AC)

a. Gunakan AC saat diperlukan, menjaga suhu ruangan tetap standar sekitar $24^{\circ} \mathrm{C}$, melakukan perawatan secara rutin.

b. Meletakan AC tidakberhadapan langsung dengan sinar matahari.

\section{Kesimpulan}

1. Pemakian energi listrik di PT. Daikin Air Conditioning Makassar adalah sebesar 111,3 kWh/m² /Tahun.

2. Dapat dilakukan penghematan sebesar $44 \mathrm{kWh} / \mathrm{bulan}$ untuk sistem penerangan. 


\section{Ucapan Terima Kasih}

Penulis tak lupa menyampaikan terima kasih kepada Direktur PNUP dan Ketua UPPM PNUP atas dukungan dana dan kesempatan untuk melakukan penelitian yang bersumber dari DIPA PNUP.

\section{Daftar Pustaka}

[1] Badan Koordinasi Energi Nasional. 1983. Buku Pedoman Tentang Cara-Cara melaksanakan Konservasi Energi dan Pengawasannya. Jakarta

[2] Lybery, MD. 1981. Source Book for Energy Auditor, International Energy Agency.

[3] Rianto.A. 2007. Audit Energi dan Analisis Peluang Penghematan Konsumsi Energi pada Sistem Pengkondisian Udara di Hotel Santika Premiere Semarang. (Tesis). Semarang: UNNES.

[4] Kementrian Energi dan sumber daya. 2010, Ministry of energy and mineral Resource, (Online),http://www.esdm.go.id. Diakases tanggal 07 Oktober 2015.

[5] Luqman Agus. 2007. Audit Energi untuk pencapaian Efisiensi Penghematan Listrik di Gedung Tower Universitas Mercubuana.

[6] Capehart BL, Turner CT and William J.Kennedy. 2003. Guide to Energy Management Fairmont press inc. Bureau of Energy Efficiency.

[7] Direktorat Pengembangan Energi. Petunjuk teknis konservasi energi; Prosedur Audit Energi Pada Bangunan Gedung. Jakarta: Departemen Pertambangan danEnergi. Direktotat Jendral Pengembangan Energi.

[8] Demang, 2011.LED : Terang, Hemat Cermat dan Bersahaja, (Online),(http://demangcorners.com/2011/09/17/led-terangdan-hemat.

[9] Energy savers. (2009). Compact fluorescent lamp. http://www.energysavers. Com. 